Diánoia, vol. 7, no. 7, 1961

\title{
KANT Y EL PROBLEMA DE LA INVERSIÓN COPERNICANA
}

I

Confieso con franqueza que la indicación de David Hume fue sencillamente la que, muchos años antes, interrumpió mi adormecimiento dogmático y dio a mis investigaciones en el campo de la filosofia especulativa una dirección completamente distinta. Estaba yo muy lejos de prestarle oídos en relación a sus conclusiones, las cuales se deducían sencillamente porque no se representó su terna en su totalidad, sino que se fijó solamente en una parte del mismo, la cual, sin tener en consideración el todo, ninguna información puede suministrar. Si se empieza por un pensamiento fundado, aunque no desarrollado, el cual nos pone en relación con otros, se puede esperar llegar más allá por medio de la reflexión continuada, como le ocurrió al perspicaz escritor, al cual hay que agradecer la primera chispa de esta luz.

Yo inquirí, pues, primeramente, si la objeción de Hume no puede presentarse en general, y pronto encontré: que la noción del enlace de causa y efecto no es, ni con mucho, la única por medio de la cual el entendimiento concibe a priori los enlaces de las cosas, sino que la Metafísica toda consiste en eso. Traté de asegurarme de su número, y por haber logrado esto según mi deseo, a saber, por un principio único, llegué a la deducción de que estas nociones, de las cuales estaba yo ahora seguro, no se derivaban de la experiencia, como Hume habia recelado, sino que brotan de la razón pura. Esta deducción, que parecía imposible a mi sagaz antecesor, la cual a nadie fuera de él se le hubiera ocurrido, aunque todos se hayan servido confiadamente de la noción sin preguntar sobre qué se fundaba su validez objetiva, esta deducción, digo yo, era la más dificil que jamás pudo ser emprendida por la Metafísica; y lo peor era que toda la Metafísica, existente dondequiera, no podia prestarme para esto el menor auxilio posible, porque aquella deducción debe, ante todo, decidir la posibilidad de la Metafísica. Por no haber limitado el problema de Hume a un solo caso, y por haber logrado extenderlo a toda la capacidad de la razón pura, pude yo progresar más seguramente, aunque siempre con lentitud, para determinar al fin, completamente y según principios generales, la esfera total de la razón pura en sus límites, así como en su contenido, lo cual era lo que necesitaba la Metafísica para desarrollar un sistema según un plan seguro.I

Con estas palabras expresa Kant, de modo claro y preciso, en qué consiste el problema fundamental que hereda filosóficamente y a cuya solución debe entregarse por completo, pues se trata de una dificultad cuya eliminación equivale nada menos que a la posibilidad de la filosofía. Pues la deducción de que las nociones de enlace entre las cosas (causalidad) no se derivan de la experiencia, sino de la razón pura, debe ser resuelta por la Metafísica; pero ya vemos que - según Kant- la posibilidad de la Metafísica depende de esa deducción. En consecuencia, debemos preguntar: ¿qué decide Kant?

1 Emmanuel Kant: Prolegómenos, prefacio. 
Pues bien, su decisión puede ser claramente comprendida sólo si antes conocemos el curso de los acontecimientos filosóficos hasta Kant.

La solución cartesiana, puede decirse, queda confinada a la doble funcionalidad, subjetiva y objetiva, de las ideas innatas. Porque, $\sin$ asomo de duda, el resto de las ideas (adventicias y ficticias) no son, en rigor de verdad, ideas. Pero ćcómo conciliar estos dos criterios cartesianos sobre la naturaleza de la idea: el de que por ser una obra del espíritu, "es tal su naturaleza que no requiere de suyo ninguna otra realidad formal que la que recibe y obtiene del pensamiento", con este otro: "que todo lo que concebimos como dado en los objetos de las ideas está objetivamente, o por representación, en las ideas mismas"? Según Descartes, es posible hacerlo, porque: "Para que una idea contenga tal realidad objetiva en vez de tal otra, debe sin duda haberla recibido de alguna causa, en la que habrá, por lo menos, tanta realidad formal como hay realidad objetiva en la idea."

Mas, como ya se ha dicho, Descartes remata, por la via de esa doble realidad de la idea, en la noción de causalidad, y de aquí su aserción de que, conforme con el principio de causalidad, el origen de las representaciones en una idea tiene que estar en la cosa representada. Ahora bien, esto último equivale a postular que el principio relacionante entre el pensamiento y la extensión, entre psique y materia, es causal. Pero esta causalidad, recordemos bien, exige como centro intermediario entre causa y efecto, la idea innata. En consecuencia, donde ésta prevalezca, se dará ese género de filosofía denominado racionalismo; en tanto que allí donde sea rechazada, en todo o en parte, veremos florecer el empirismo.

Comencemos por este último. Su iniciador, John Locke, lleva a cabo una operación curiosa e interesante, que consiste en partir de la acepción cartesiana de la palabra cogitatio: el fenómeno psiquico en general. Entonces, ipor qué no arrancar de la sensación, en vez de afianzarse desde el principio en la idea clara y distinta, que es la idea innata? Si ha de haber una verdadera causalidad, no debe buscarse ésta en una vinculación tan precaria y discutible como esa que es menester establecer entre la representación y lo representado, sino en la primaria manifestación de esto último, que es justamente la sensación. Pues toda percepción nos entrega dos géneros diferentes de cualidades o notas caracterizantes de las cosas reales, a saber: las cualidades primarias (extensión, forma, movimiento, impenetrabilidad, etc.) y las cualidades secundarias (color, olor, sabor, temperatura, etc.). Ahora bien, estas últimas no están realmente - necesariamente_ en los objetos, porque son modificaciones totalmente subjetivas del espiritu o psique. $\mathrm{Y}$ ¿cómo lo sabemos? Pues, por una parte, porque no son constantes en la totalidad de las cosas - como sí ocurre con las primarias-, y después porque reflexionamos sobre ellas una vez que se han constituido en esas modificaciones subjetivas de nuestra psique. Pero, es preciso preguntar, ¿y las cualidades prima- 
rias no se descubren de la misma manera? Consecuente con su posición, Locke nos dice que éstas son descubiertas después de las secundarias, más bien en el acto de reflexión que sigue a éstas, pero no se derivan de ellas, sino que son autónomas. Lo cual se debe a que Locke no se desentiende totalmente de Descartes, como lo prueba su subordinación al criterio sustancialista del mismo. Así, por ejemplo, en su tercera carta a Stillingfleet, dice que "hay sustancia porque no podemos concebir de qué modo las cualidades puedan subsistir por sí mismas". ${ }^{2}$

Que Locke sigue en cierto modo, si no a la letra, al menos en el espíritu, la doctrina cartesiana de las ideas innatas, por lo menos en lo que afecta a la función de éstas, lo dan a entender estos pasajes de su obra fundamental:

El tener ideas gencrales es lo que establece una perfecta distinción entre el hombre y las bestias, y es una perfección que las facultades de las bestias no alcanzan de ningún modo. Pues es evidente que no observamos rastros de que hayan hecho uso de signos generales para ideas universales, por lo cual tenemos derecho a suponer que ellas no tienen la facultad de abstraer o de formarse ideas generales, ya que no hacen uso de palabras o de otros signos generales. 3

Y un poco más adelante, al indagar cómo es que si las cosas que existen son particulares, es posible llegar a las ideas generales, declara:

Las palabras se tornan (become) generales cuando se las toma como signos de las ideas generales.4

Berkeley, como sabemos, no sólo comparte el punto de vista de Locke de que es preciso arrancar de la sensación, sino que va mucho más lejos, puesto que no admite separación alguna entre cualidades primarias y secundarias.

Deseo que se reflexione y se trate de concebir por medio de una abstracción del pensamiento, la extensión y el movimiento de un cuerpo sin todas las otras cualidades sensibles. Por mi parte veo con toda evidencia que no está en mi poder formar una idea de un cuerpo extenso y en movimiento, sin añadirle algún color $u$ otra de las cualidades sensibles que se admite existen sólo en la mente.5

Y a mayor abundamiento, en el primero de los Diálogos:

¿No se admite acaso que el calor y el frío no se hallan en el agua, puesto que ésta parece caliente a una mano y fria a otra? Pues bien, ¿no es lo mismo concluir que no existe extensión o figura de un objeto puesto que éste parece pequeño, suave y redondo a un ojo, mientras que al mismo tiempo aparecerá grande, desigual y anguloso a otro? 6

2 Third Letter to Stillingfleet, "The Works of John Locke", $10^{\text {a }}$ ed., Londres 1810. 3 John Locke: Ensayo sobre el entendimiento humano, libro II, cap. 11 , $\S 10$ y 11. 4 Ibid., libro III, cap. $3, \S 6$.

5 George Berkeley: Tratado sobre los principios del conocimiento humano, sec. 10. 6 G. Berkeley: Tres diálogos entre Hilas y Filonus, I. 
Por consiguiente, la extensión no tiene existencia sino en una mente que la piense; mas si la materia no es identificable con la extensión, sin el conjunto de todas las cualidades, para que sea inexistente fuera de la mente es preciso demostrar la subjetividad de todas las cualidades primarias, lo cual no es difícil, ya que si

la extensión no tiene existencia fuera de un espiritu, debe concederse lo mismo del movimiento, la solidez y la gravedad, ya que éstas suponen, evidentemente, la extensión.T

El conocimiento es, pues, conocimiento de lo percibido, lo cual significa la absoluta imposibilidad, no de la existencia del mundo exterior, que Berkeley no niéga ["cuando abro los ojos en pleno día, no está en mi poder elegir si veré o no, o determinar qué objeto particular se presentará a mi vista", Trat., sec. 29], sino de su independencia respecto del sujeto cognoscente. ¿Cómo vamos, entonces, a concebir la materia como algo fuera de la mente, si el hecho de concebir implica la necesidad de que sea en y por una mente? Tal intento es sencillamente absurdo. Pues si la materia no existe, ¿qué es lo percibido? Berkeley responde así:

Es en realidad opinión extrañamente dominante entre los hombres, que las casas, las montañas, los rios, y en una palabra todos los objetos sensibles, tienen una existencia natural o real distinta de su ser percibidos por el entendimiento. Pero a pesar de lo firme y admitido que este Principio pueda estar en el mundo, cualquiera que en sí mismo sienta la necesidad de ponerlo en duda puede, si no me equivoco, percibir que él encierra una contradicción manifiesta. Pues ¿qué son los objetos antes mencionados sino las cosas que percibimos por los sentidos? ¿Y qué percibimos fuera de nuestras propias ideas o sensaciones? ¿Y no es simplemente chocante, que cualesquiera de ellas, o cualquier combinación de ellas exista como no percibida?

Si examináramos atentamente esta creencia, se encontrará posiblemente que ella depende, en última instancia, de la doctrina de las ideas abstractas. Pues, ¿puede haber un esfuerzo de abstracción más refinado que distinguir la existencia de los objetos sensibles de su ser percibidos, hasta el punto de concebirlos como existentes sin ser percibidos? La luz y los colores, el calor y el frío, la extensión y las figuras -en una palabra, las cosas que vemos y sentimos_ ¿qué son sino diversas sensaciones, nociones, ideas o impresiones de los sentidos? ¿Y es posible separar, aunque sea en el pensamiento, alguna de éstas de la percepción? Por mi parte podría con la misma facilidad dividir una cosa de sí misma. Puedo en verdad, dividir en mis pensamientos, o concebir separadas unas de otras aquellas cosas que, por los sentidos, posiblemente nunca percibí divididas... Pero mi poder de concebir o imaginar no se extiende más allá de la posibilidad de una existencia o percepción real. Por lo tanto, así como me es imposible ver o sentir cualquier cosa, sin una sensación presente de esa cosa, me es imposible también concebir en mis pensamientos cualquier cosa u objeto sensible, distinta de su sensación o percepción.8

He aquí, pues, a la abstracción como lo que opone el obispo de Cloyne a la conciliación cartesiana del acto subjetivo del pensamiento con la realidad objetiva. Pues si Locke parte de la sensación (el espíritu o la mente es

7 Ibid., I.

8 G. Berkeley: Tratado, ob. cit., 4, 5. 
a white paper), Berkeley afina este concepto de su ilustre antecesor y nos dice que si "extensión, figura y el movimiento son sólo ideas que existen en la mente", "es obvio que la misma noción de lo que se llama materia o sustancia corpórea, implica una contradicción". 9 Y si la abstracción alcanza a la materia, ¿qué ocurrirá con sus conexiones con el pensamiento? Se advertirá sin esfuerzo que nos referimos a la causalidad, sin la cual, a partir de Descartes, no es posible recuperar el mundo exterior.

Hume es quien lleva la cuestión al otro extremo donde la encuentra Kant al despertar de su "adormecimiento dogmático", que ya veremos en qué consiste. Y Hume parte de la distinción entre impresiones e ideas, aunque para él toda idea procede de una impresión, pero también hay ideas cuyo origen (las impresiones que deben haberlas motivado) no es posible determinar, v. gr., las de existencia, sustancia, causa, yo, etc. Pues bien, estas ideas son ficciones y de ellas probablemente no haya ninguna tan ficticia como la idea de causa y efecto. Que $A$ es la causa de $B$ no quiere decir sino que $B$ sigue a $A$, porque se trata pura y simplemente de una "asociación de ideas".

... en total, no aparece en toda la naturaleza un solo caso de conexión que sea concebible por nosotros. Todos los sucesos parecen enteramente sueltos y separados. Un suceso sigue a otro, pero jamás podemos observar un lazo entre ellos. Parecen ayuntados, pero no conectados y como no tenemos idea de algo que jamás ha aparecido a nuestros sentidos exteriores o a nuestro sentimiento interno, la conclusión necesaria parece ser que no tenemos por completo idea de conexión o fuerza y que estas palabras carecen de todo significado tanto cuando se emplean en razonamientos filosóficos como cuando se emplean en la vida diaria.

Pero aún queda un método para evitar esta conclusión, y una fuente que todavía no ha sido examinada. Cuando se presenta algún objeto natural o suceso, ninguna sagacidad ni penetración nos hace posible descubrir, o aun conjeturar, sin auxilio de la experiencia, qué suceso resultará de ello, o de llevar nuestra revisión más allá del objeto que está inmediatamente presente en la memoria y los sentidos. Aun después de un caso o experimento en que hemos observado que un suceso particular sigue a otro no tenemos derecho a formar una regla general o a predecir qué ocurrirá en casos iguales. Sería tenido por imperdonable temeridad - y con razón - juzgar acerca de todo el curso de la naturaleza por un solo experimento, por más preciso y cierto que fuese. Pero cuando una clase particular de sucesos, siempre y en todos los casos ha estado ayuntada a otra, no tenemos inconveniente en predecir el uno al aparecer el otro y en emplear ese razonamiento que sólo puede asegurarnos acerca de hechos o cosas existentes. Entonces a un objeto lo llamamos causa y al otro efecto. Suponemos que hay alguna conexión entre ellos, alguna fuerza en uno por la cual infaliblemente produce el otro y actúa con la máxima certeza y con la más fuerte necesidad.

Parece, pues, que esta idea de una conexión necesaria entre los sucesos surge de un número de casos similares en que ocurre la ayuntación constante de estos sucesos, ya que esa idea no puede ser sugerida por ninguno de estos casos, aunque fueran examinados por todos sus costados y desde todos los ángulos. Pero en un número de casos supuestos similares unos de otros, no hay diferencia con cada uno de los casos aislados, salvo que después de la repetición de casos similares, el espíritu es conducido por el hábito a esperar su

9 Ibid., sec. 9 . 
acompañante usual y a creer que existirá. Por tanto, esta conexión que nosotros sentimos en el espíritu, esta acostumbrada transición de la imaginación de un objeto a su acompañante usual, es el sentimiento o impresión del cual formamos la idea de Fuerza o de conexión necesaria.10

Mas la experiencia nos deja... ien la experiencial con respecto a la causalidad, lo que equivale a decir que no es posible establecer relación alguna entre el pensamiento y la extensión. Entonces, ¿a qué se reduce la Ciencia (el conocimiento en general) si ella se funda en hábitos, costumbres, asociaciones de ideas? Anticipando un poco lo que después desarrollaremos en detalle, digamos ahora que el proceso aniquilador de uno de los extremos de la correlación cartesiana acto subjetivo del pensamiento-realidad objetiva, o sea de este último, tal como se efectúa desde Locke a Hume, es posible porque ellos siguen adscribiendo las categorías, mediante las cuales es posible conocer, a la realidad exterior, o sea al objeto. Pero es que esto mismo es lo que hacen los sucesores de Descartes en el Continente. Veamos cómo.

Entre la afirmación cartesiana de que hay ideas innatas y la de Locke de que no las hay, va a situarse Leibniz con su teoria de las verdades de hecho y las verdades de razón. Admitamos en un comienzo que no hay ideas claras y distintas (innatas), sino solamente ideas confusas y oscuras, o sea todas esas que la mente debe someter a rigurosa inspección. Pero si estas últimas pueden llegar a convertirse en ideas claras y distintas, es porque nacen de gérmenes oscuros implícitos en nuestra razón.

Para comprender mejor la naturaleza de las ideas, hay que decir algo sobre la variedad de los conocimientos. Cuando puedo reconocer una cosa entre otras, sin poder decir en qué consisten sus diferencias o propiedades, el conocimiento es confuso. Es así como a veces conocemos claramente, sin tener ninguna duda, si un poema o un cuadro están bien o mal hechos, porque hay un no sé qué que nos satisface o nos choca. Pero cuando puedo explicar los signos que tengo, el conocimiento se llama distinto...

Pero el conocimiento distinto tiene grados, pues ordinariamente las nociones que entran en la definición han menester de definición y sólo se las conoce confusamente. Pero cuando todo lo que entra en una definición o conocimiento distinto se conoce distintamente, hasta sus nociones primitivas, llamo a este conocimiento adecuado. $Y$ cuando mi espíritu comprende a la vez y distintamente todos los ingredientes primitivos de una noción, se tiene entonces un conocimiento intuitivo, que es muy raro, siendo la mayor parte de los conocimientos humanos confusos o supositivos.11

$\mathrm{Y}$ de aquí la postulación leibniziana de dos clases de verdades, unas de razón y otras de hecho.

Hay también dos clases de verdades: las de razón y las de hecho. Las verdades de razón son necesarias y su opuesto es imposible; y las de hecho son contingentes y su opuesto es posible. Cuando una verdad es necesaria puede encontrarse su razón por medio del análisis, resolviéndola en ideas y verdades más simples, hasta llegar a las primitivas.12

10 David Hume: Investigación sobre el entendimiento humano, sec. vı, $2^{\text {a }}$ parte.

11 G. F. Leibniz: Discurso de metafisica, sec. xxiv.

12 Monadologia, sec. 33 . 
Es indudable, entonces, que Leibniz admite la existencia de las ideas innatas, no solamente porque, en definitiva, las verdades de razón pueden desarrollarse hasta dar con su punto de partida, sino, además, porque el conocimiento llamado distinto supone llegar hasta las nociones primitivas.

Para concebir bien lo que es la idea, hay que prevenir una equivocación, pues muchos toman la idea por la forma o diferencia de nuestros pensamientos, y de esta manera no tenemos la idea en el espíritu sino en tanto que pensamos en ella, y cuantas veces pensamos de nuevo en ella tenemos otras ideas de la misma cosa, aunque semejantes a las precedentes. Pero parece que otros toman la idea por un objeto inmediato del pensamiento o por una forma permanente que persiste cuando no la contemplamos. $Y$, en efecto, nuestra alma tiene siempre en sí misma la cualidad de representar cualquier naturaleza o forma, sea cual fuere, cuando se presenta la ocasión de pensar en ella. Y creo que esta cualidad de nuestra alma, en tanto que expresa alguna naturaleza, forma o esencia, es propiamente la idea de la cosa, que está en nosotros, y que siempre está en nosotros, ya pensemos en ella o no.13

Ahora bien, ¿por qué no llevar el innatismo hasta sus últimas consecuencias? Esto es lo que hace Leibniz, tanto en su teoría del cálculo infinitesimal (extensión) como en la teoría de las mónadas (pensamiento). Con lo cual aspira a resolver dos cuestiones, a saber: por una parte, el problema de la comunicación de las sustancias (interacción de cuerpo y alma), y por otra el problema de reducir el innatismo a su estricta dimensión, lo que, en concepto de Leibniz - como lo haremos ver- consiste en decir no que hay innatismo, sino que todo es innato.

Le calcul des infiniment petits es consecuencia de convertir la idea cartesiana del espacio puramente geométrico en espacio físico (concreto), para que sea posible la explicación del movimiento. Con el cálculo diferencial es posible descubrir la exacta formulación de lo que distingue al punto de la recta y la curva respectivamente; y con el integral determinar qué dirección - por consiguiente, qué naturaleza - va a tener la recta, la curva, la elipse, etc. $O$ sea cuál va a ser la dirección seguida por el punto mismo. Luego en el punto encontramos, en germen, la extensión y la figura, ¿de qué?, ¡ah! del mundo real, concreto, a través del movimiento de ese punto que, como vemos, engendra espacio, figura y movimiento.

Pasemos ahora al correlato de la extensión, pero, eso sí, concebido también "puntualmente": he aquí la mónada leibniziana. Ésta es sustancia, como realidad, pero no como extensión, pues el cálculo infinitesimal nos ha revelado ya que la extensión es el orden de las sustancias (de los puntos), es decir, el orden de su simultaneidad: en consecuencia, el espacio es solamente una idea previa, que, por esto mismo, carece de realidad. Y lo único que hace falta entonces es que a ese orden de simultaneidad de las sustancias (de los puntos) corresponda otro orden, el de la sucesión de los estados

13 Discurso de metafisica, sec. xxvi. 
de conciencia del hombre, o sea el tiempo; y este segundo orden corresponde a la mónada (el espiritu o la res cogitans). Como se advierte ahora claramente, a la "puntualidad" de la sustancia extensa (el punto matemático) corresponde esa otra "puntualidad" de la mónada, la cual se caracteriza del mismo modo que el punto en cuanto que no hay dos mónadas iguales, pues entonces serían una sola; como tampoco hay dos puntos iguales, sino que cada uno de los que forman la línea es diferente, como que es otro, a los demás, pues si fuera siempre el mismo, tendríamos entonces un espacio geométrico; mientras que siendo cada uno distinto, e independiente de los demás, él es expresión de esa realidad física de la cual es porción infinitesimal.

Mas ¿por qué establece Leibniz esta similitud entre las respectivas "puntualidades" de la extensión y el pensamiento? Por lo siguiente: así como la figura y su extensión están germinalmente en el punto, así también la mónada es siempre una reducción del mundo entero: por consiguiente, la mónada refleja el universo, o sea que en ella se contiene - perceptualmenteel esquema de otras mónadas que son los infinitos puntos que dibuja la realidad exterior.

Ahora bien, este enlace o acomodo de todas las cosas creadas con cada una y de cada una con todas las demás, hace que cada sustancia simple tenga relaciones que expresan todas las demás, y sea, por consiguiente, un espejo viviente y perpetuo del universo.14

\section{II}

Por ambas vías, empirismo y racionalismo, se desemboca en la misma conclusión: que la causalidad es imposible. La idea de causalidad es para Hume sólo un hábito o —como también dice- una "asociación de ideas". Mientras que Leibniz rechaza toda intromisión del mundo exterior en la interioridad sans fenêtres de la mónada y afirma que la posibilidad de interacción se debe a una armonía preestablecida. Por consiguiente, la ciencia que Hume niega realmente, es negada virtualmente por Leibniz. En consecuencia, el conocimiento o es un azar (Hume) o un milagro (Leibniz).

Es aquí precisamente donde Kant entra en acción, pues lo primero que hace es advertir que la metafísica, hasta él, es ontologia; y ésta consiste en postular determinadas características "fundamentales" de un ser puro y sim. ple (ser en sí), para tratar después de conocerlas. Ahora bien, en esta dificultad de origen incurre lo mismo el racionalismo que el empirismo, pues aunque se diferencian en los medios de alcanzar el conocimiento (razón o sentidos), concuerdan en la creencia en ese ser primario y que nuestra sub. jetividad puede reflejar. Pero Kant nos dice que si la metafísica ha de subsistir, es preciso que en lugar de empeñarse en la elaboración de doctrinas sistemáticas sobre las "cosas en general", se conforme con ser una simple

14 Monadologia, sec. $5^{6}$. 
analítica del entendimiento puro. Si la metafísica tradicional procede de este modo: pregunta primero qué es el ser, y después pone de manifiesto cómo se revela al entendimiento; la metafísica, según la concibe Kant, ha de partir de la definición de lo que significa en general el problema del ser. Cassirer expone muy claramente la cuestión con estas palabras:

Mientras que antes se tomaba cualquier estructura determinada del mundo de los objetos como un comienzo seguro y el problema consistía simplemente en mostrar cómo esta forma de la "objetividad" se trocaba en la forma de la "subjetividad", en conocimiento y en ideas, ahora se exige que antes de formular ninguna teoría acerca de este tránsito de lo objetivo a lo subjetivo se explique qué significan en términos generales el concepto de la realidad y el postulado de la objetividad. Pues la "objetividad" - cosa que ahora se ve, pero que no se habia visto antes - no es precisamente un estado de cosas primigenio y no susceptible ya de seguir siendo desintegrado, sino que es un problema originario de la "razón", problema que tal vez no pueda ser resuelto íntegramente, pero acerca de cuyo sentido cabe rendir, desde luego, cuentas completas y seguras.15

Ya en la carta a Marcus Herz - de 21 de febrero de 1772 - se plantea Kant el problema de la verdadera naturaleza y, por consiguiente, de las funciones que le están asignadas al entendimiento. $\mathbf{Y}$ a este respecto dice lo que sigue:

Pero ¿cómo nuestro entendimiento puede, en el plano de las cualidades, formarse totalmente a priori conceptos de las cosas con los que éstas coincidan totalmente? ¿Cómo puede forjarse principios reales acerca de su posibilidad con los que la experiencia haya de coincidir fielmente y que, sin embargo, sean independientes de ella? Este problema deja siempre un rastro de oscuridad con respecto a nuestra capacidad para entender de dónde puede sacar el intelecto esta coincidencia con las cosas.16

He aquí, pues, el problema que confronta Kant en un comienzo, puesto que se trata del que le ha legado el proceso filosófico que remata en Hume y Leibniz. Pues mientras no se sepa, con la debida claridad, cómo se opera ese pasaje desde el objeto al sujeto, si es que realmente lo hay, la dificultad suscitada por Hume permanece incólume. De aquí que vuelva Kant sobre esta cuestión en la Crítica de la razón pura.

Es, pues, necesario ponerse de acuerdo aquí acerca de lo que se entiende por la expresión de objeto de las ideas... ¿Qué se entiende, por tanto, cuando se habla de un objeto que corresponde al conocimiento o difiere de él? Es fácil comprender que este objeto sólo puede $\mathrm{y}$ debe concebirse como algo $=\mathrm{X}$, ya que fuera de nuestro conocimiento no tenemos nada que podamos enfrentarle como algo correspondiente a él. Pero encontramos que nuestra idea de la relación de todos los conocimientos con su objeto entraña algo necesario, ya que éste se considera, en efecto, como aquello que se opone a que nuestros conocimientos se determinen al buen tuntún o caprichosamente y quiere que se determinen $a$ ṕriori de un determinado modo, puesto que, debiendo relacionarse con un objeto, deben también coincidir los unos con los otros con respecto a éste, es decir, poseer aquella unidad que

15 E. Cassirer: Kant, vida y doctrina, III, 2.

16 Ibid., I, 5 . 
corresponde al concepto de un objeto... Y entonces decimos: conocemos al objeto cuando hemos llegado a una unidad sintética dentro de la variedad de la intuición... Asi concebimos un triángulo como objeto al tener conciencia de la agrupación de tres líneas rectas conforme a una regla a tono con la cual tenemos que representárnoslo siempre. Ahora bien, esta unidad de la regla determina todo lo múltiple y lo circunscribe dentro de condiciones que hacen posible la unidad de la apercepción; el concepto de esta unidad es la idea del objeto $=\mathrm{X}$ que concibo mediante los predicados mentales de un triángulo.17

Con estas palabras tocamos directamente el fondo de la cuestión propuesta, pues el concepto de la unidad de la regla, que es "la idea del objeto", indica cuál va a ser la nueva dirección que va a tomar Kant, con la cual - casi no hay que decirlo_ estamos a un paso de su famosa "inversión copernicana". Como dice Cassirer, "la necesidad del juicio no proviene de la unidad de un objeto detrás del conocimiento y más allá de él, sino que es esta necesidad la que constituye para nosotros el único sentido concebible de la idea del objeto".18 De manera que Kant sustituye la tradicional noción de un mundo de ideas que es trasuntọ de un mundo de cosas, por esa otra suya, según la cual, "la existencia de juicios incondicionalmente ciertos" determina "que exista para nosotros una ordenación que debe ser considerada, no simplemente como una ordenación de impresiones e ideas, sino también como una ordenación de objetos". ${ }^{19} \mathrm{Y}$ de esta manera, ya de modo textual y taxativo, expresa Kant en el prólogo a la segunda edición de la Crítica de la razón pura:

Hasta aquí entendíase que todos nuestros conocimientos debian ajustarse a los objetos; pero, partiendo de esta premisa, se venían a tierra todos los intentos que se hacian para averiguar a priori algo acerca de ellos por medio de conceptos que ampliaran nuestros conocimientos. Por eso debemos esforzarnos en ver si no conseguiremos mejores resultados en los problemas de la metafísica partiendo del supuesto de que los objetos deben ajustarse a nuestro conocimiento, el cual coincidirá mejor así con la postulada posibilidad de un conocimiento a priori de los mismos que nos diga algo acerca de los objetos antes que éstos nos sean dados. Ocurre con esto algo así como con las primeras ideas de Copérnico, el cual, después de comprobar que no progresaba gran cosa en la explicación de los movimientos celestes a base del supuesto de que todo el firmamento giraba alrededor del que lo contemplaba, decidió ver si no darla mejor resultado el hacer que girase el espectador y que los astros permaneciesen quietos.20

Ahora bien, para entender como se debe la revolucionaria hazaña en que consiste esta inversión, es preciso que antes nos pongamos en claro acerca de ciertos supuestos kantianos, de los cuales el primero es el de la trascendentalidad. De antiguo son conocidos en la historia de la filosofía los conceptos de trascendencia e inmanencia, ligados respectivamente al realismo

17 E. Kant: Critica de la razón pura, "Teoria elemental trascendental", sec. $2^{\mathfrak{a}}$, cap. $\mathrm{n}, 15$.

18 E. Cassirer: $O p$. cit., III, 2.

19 lbid.

20 E. Kant: Critica de la razón pura, prólogo a la $2^{2}$ edición. 
y al idealismo; pero ahora Kant, que como hemos visto invierte la relación cognoscitiva sujeto-objeto y además la dinamiza al hacer del juicio la posibilidad misma del objeto; Kant, decimos, va más allá de la inmanencia y la trascendencia y postula que el conocimiento trascendental es aquel que se refiere, no tanto al objeto mismo, como al modo que tiene el sujeto de conocerlo, siempre que dicho conocimiento sea a priori. $\mathrm{Y}$ conforme con esto expresa lo siguiente:

De aquí que no tengan, ni mucho menos, el carácter de ideas trascendentales aprio. rísticas el espacio ni una determinación geométrica cualquiera del mismo, sino que lo único que puede llamarse trascendental es el conocimiento de que estas ideas no tienen en modo alguno origen empírico y la posibilidad de recaer también a priori sobre los objetos de la experiencia.21

Por consiguiente, de la peculiaridad de la función de conocimiento depende la peculiaridad del objeto del conocimiento; de lo cual resulta que todos los conceptos fundamentales (espacio, tiempo, categorías) llevan implícito el atributo de la subjetividad, lo que significa que el punto de partida no es el objeto sino ciertas leyes específicas del conocimiento. Y de este modo, al aplicar la trascendentalidad al espacio, encontramos que la "esencia" de éste no requiere el análisis de la "idea de espacio" - ya dada al sujeto como proveniente de fuera-, sino que el sujeto parte, en la comprensión de la esencia del espacio, de la previa comprensión de la naturaleza del conocimiento geométrico. Dicho de modo más claro: que no se va del espacio a las formas geométricas, sino al revés, de éstas a aquél.

... El primero que demostró el triangulo equilatero (fuese Tales o quien haya sido) vio ya una luz en el horizonte, pues se dio cuenta de que no necesitaba aprender de lo que veía en la figura ni en el simple concepto de ella, o copiar sus propiedades, sino que tenía que representarse el modo como la concebía y se la imaginaba por medio de conceptos a priori (mediante la construcción) y de que, para saber algo a priori con certeza, no necesitaba atribuir a la cosa nada que no se desprendiera necesariamente de su mismo concepto.22

Sí, afirma Kant, la construcción geométrica es "anterior" a la figura geométrica, pues el sentido de ésta proviene de su construcción, y no al revés. Por eso no se puede decir que los casos geométricos sean algo distinto e independiente de la ley a la cual se deben, sino que emergen de la conciencia de esa ley. $Y$ por eso puede Kant llegar a decir que lo único que sabemos a priori de las cosas es lo "que nosotros mismos ponemos en ellas". 23

Y llegamos así, tras los conceptos fundamentales de lo "subjetivo" y lo "trascendental", al tercero de los que forman el asiento de la crítica de la razón: me refiero al concepto de "síntesis a priori". Para entender ésta es

21 E. Kant: Critica de la razón phura, "Lógica trascendental", sec. $\mathbf{}$

22 E. Kant: Critica de la razón pura, $2^{\circ}$ prólogo.

23 Ibid. 
conveniente comenzar comparando lo que ocurre en los simples juicios empíricos, en los cuales se da una agrupación de elementos sueltos que los juicios lógico-formales desintegran y analizan, con lo que sucede en la síntesis a priori. Para captar el significado de ésta es preciso partir del carácter intuitivo a priori que poseen el espacio y el tiempo, pues todo conocimiento sintético-aprioristico implica una relación entre lo infinito y lo finito, entre lo general y lo particular-concreto de la otra. De aquí que diga Kant en la Estética trascendental, refiriéndose al tiempo, algo que puede ser suscrito igualmente con referencia al espacio.

La naturaleza infinita del Tiempo significa que toda cantidad determinada de Tiempo es solamente posible por las limitaciones de un único Tiempo que les sirve de fundamento. Por lo tanto, la representación primitiva del Tiempo debe ser dada como ilimitada. Pero cuando las partes mismas y cantidades todas de un objeto sólo pueden ser representadas y determinadas por medio de una limitación, de ese objeto no puede entonces la representación toda ser dada por conceptos (porque éstos sólo contienen representaciones parciales), sino que deben tener como fundamento una intuición inmediata.24

Pero ¿y la ciencia física? Pues ya hemos visto que es posible una ciencia de conceptos puros (mátemáticas) con validez ideal, tanto como una ciencia descriptiva integrada por observaciones reales concretas de objetos dados. Mas, ¿para llegar a una ciencia matemática de la naturaleza? A esta cuestión responde Kant en el segundo prólogo:

Cuando Galileo hizo que sus esferas rodasen por el plano inclinado con una gravedad elegida por él mismo, o cuando Torricelli hizo que el aire soportase un peso que él había concebido de antemano como igual al de una columna de agua por él conocida, o en una época posterior Stahl convirtió algunos metales en cal y ésta nuevamente en metal, sustrayendo o reponiendo algunos elementos propios de aquéllos, todos los investigadores de la naturaleza empezaron a ver claro. Diéronse cuenta de que la razón sólo comprende aquello que ella misma produce con arreglo a sus propios designios; que ésta debe proceder en sus juicios según leyes constantes y obligar a la naturaleza a contestar a las preguntas que la misma razón le formule, sin dejarse llevar por ella como por unas andaderas, por decirlo asi, pues de otro modo nos encontrariamos con que las observaciones fortuitas, no ajustadas a un plan previo, no se coordinan con sujeción a una ley necesaria, que la razón busca siempre y necesita. La razón debe abordar la naturaleza llevando en una mano sus prin. cipios sin los cuales no podrian nunca regir como leyes los fenómenos coincidentes, y en la otra el experimento concebido por ella conforme a aquellas leyes, buscando ciertamente las enseñanzas de la naturaleza, pero no al modo del discípulo que repite de carrerilla cuanto quiere el maestro, sino a la manera del juez que obliga a los testigos a contestar a las preguntas que él les hace. Y asi, hasta la misma fisica debe la ventajosa revolución operada en su modo de pensar a la ocurrencia de buscar en la naturaleza (buscar en ella y no atribuirle), con arreglo a lo que la razón misma pone en ella, lo que de ella necesariamente tiene que aprender y que en modo alguno llegaría a saber por sí misma. Esto es lo que ha hecho marchar primerísimamente a la ciencia de la naturaleza por el derrotero

24 E. Kant: Critica de la razón pura, "Teoría elemental trascendental", primera parte, sec. II, 4 . 
seguro de una ciencia, sacándola de aquel terreno de los simples tanteos en que durante tantos siglos se había movido.25

Desde luego que esto es posible -en la ciencia moderna_- en cuanto transitamos desde el concepto de naturaleza entendida como el conjunto de los objetos físicos y materiales a este otro que propone Kant, o sea: que la naturaleza "es la existencia de las cosas, en cuanto determinada por leyes generales". Por consiguiente, si bien él ha comenzado concibiendo la naturaleza como el conjunto de todos los objetos de la experiencia, vemos que concluye considerándola - desde un punto de vista eminentemente formalcomo la adecuación a leyes de todos sus objetos. $\mathrm{Y}$ así dice en los Prolegómenos:

Aqui trataremos, pues, simplemente de la experiencia y de las condiciones generales y aprioristicas de su posibilidad, determinando a base de ello la naturaleza como el objeto total de toda experiencia posible. Creo que se me comprenderá si digo que no me refiero aquí a las reglas de observación de una naturaleza ya dada..., sino a cómo las condiciones aprioristicas de la posibilidad de la experiencia son, al mismo tiempo, las fuentes de las que deben derivarse todas las leyes generales de la naturaleza.26

La "síntesis a priori" responde, pues, a la misma idea fundamental que sirve de eje a la inversión copernicana, de manera que también la naturaleza, concebida como lo fenoménico, debe ajustarse a los requisitos de la inversión. Porque si bien son muchas las leyes conocidas, sólo en la experiencia,

... las leyes que rigen la concatenación de los fenómenos, es decir, la naturaleza en general, no pueden sernos reveladas por ninguna experiencia, ya que la experiencia misma presupone, a su vez, la existencia de tales leyes, que sirvan a priori de base a su posibilidad.27

\section{Finalmente:}

Es cierto que las leyes empíricas como tales no pueden derivar su origen en modo alguno del entendimiento puro, del mismo modo que la infinita variedad de los fenómenos no puede ser suficientemente comprendida a base de la forma pura de la intuición de nuestros sentidos. Pero todas las leyes empíricas son, simplemente, determinaciones especiales de las leyes puras del entendimiento con sujeción a las cuales y con arreglo a cuyas normas son posibles aquéllas y revisten los fenómenos una forma legal, del mismo modo que todos los fenómenos, pese a la diversidad de su forma empírica, tienen necesariamente que ajustarse en cada caso a la forma pura de la sensoriedad.28

Los tres conceptos ya analizados, es decir, la subjetividad, la trascenden. talidad y la "síntesis a priori", son los que permiten comprender, a su vez, esas otras cuestiones que constituyen la esencia de la epistemología kantiana

25 E. Kant: Critica de la razón pura, $2^{9}$ prólogo.

26 E. Kant: Prolegómenos, 14, 17.

27 Ibid., $3^{6 .}$

28 E. Kant: Critica de la razón pura, Introducción. 
y prefiguran una posible metafísica. Me refiero a los "juicios sintéticos a priori", a las intuiciones puras de espacio y tiempo, y a las categorias. Con su inspección, habremos conseguido situarnos en el mismo centro de la finalidad propuesta por la inversión copernicana.

\section{III}

a) El "juicio sintético a priori"

Una observación cuidadosa de la forma en que aparecen sucesivamente en la filosofía kantiana los conceptos de "subjetividad", "trascendentalidad" y "sintesis a priori", permite concluir que se trata de la misma tesis, aunque manifiesta en distintos modos. "No significa esta 'subjetividad' en modo alguno - dice Cassirer-, que se partiera de la organización del individuo cognoscente ni de los procesos psicológicos a través de los que nace, para él, el mundo de las sensaciones, de las ideas y de las asociaciones de ideas." 29 El sujeto es ahora la razón misma; de manera que a toda determinación del objeto del conocimiento ha de preceder la determinación de la forma pura del conocimiento. Y si el conocimiento "trascendental" es el que se refiere, no tanto al objeto mismo, como al modo que tiene el sujeto de conocerlo, siempre que este conocimiento sea a priori, no cabe duda de que la trascendentalidad es una de las formas en que se puede presentar la subjetividad. Mas ¿es posible una trascendentalidad entendida como modo o forma de conocer el sujeto apriorísticamente el objeto, a menos que ella sea una síntesis a priori de las condiciones que hacen posible el conocimiento en general? Por eso el yo kantiano no es una entidad diferente e independiente del objeto, que puede hasta precederle o disfrutar de la prerrogativa de una existencia que se le regatea al objeto (Descartes) o se le niega de modo terminante (Berkeley). Originariamente, el yo no es una simple sustancia, sino que "su idea nace en nosotros a base de las mismas sintesis, de las mismas funciones de asociación de lo múltiple que convierten el contenido de la percepción en contenido de experiencia, la 'impresión' en 'objeto' ".30 Y que esta sintesis es responsable del yo y al mismo tiempo su perfecto equivalente, lo deja claramente establecido Kant en este pasaje de la Critica de la razón pura:

Toda la reproducción de la serie de las ideas seria en vano sin la conciencia de que lo que pensamos ahora es exactamente lo mismo que pensábamos hace un momento. Pues en otro caso sería una idea nueva en el estado actual, que para nada pertenecería al acto por medio del cual es engendrada poco a poco, y la variedad de la misma no constituiria nunca un todo, ya que carecería de la unidad que sólo puede darle una conciencia. Si al

29 E. Cassirer: Op. cit., III, 4.

30 Ibid. 
contar me olvidase de que las unidades que ahora tengo presentes han sido añadidas poco a poco a mí, no tendría conciencia de la creación de la cantidad mediante esta adición sucesiva de unidades, ni, por tanto, tendría conciencia del número. La palabra "concepto" podría servirnos ya de por sí de guía para esta reflexión. Pues es esta conciencia única la que une en una idea lo múltiple, lo intuido por nosotros poco a poco, y también lo reproducido. Puede ocurrir, y ocurre con frecuencia, que esta conciencia sea tenue, de tal modo que sólo la asociemos al efecto, no al acto mismo, es decir, directamente al alumbramiento de las ideas; pero, a despecho de estas diferencias, tiene que existir una conciencia, aunque no brille en ella la claridad, pues sin ella serfan imposibles los conceptos y, por tanto, el conocimiento de los objetos.31

El yo no es, pues, el resultado o la consecuencia de las diferentes percepciones; él es un punto de referencia constante que engrana las múltiples variedades de lo particular en una significación cuya cualidad fundamental y decisiva es la de ser contenido de conciencia; por lo que - dice Kant"toda conciencia pertenece a una percepción pura y omnicaptatoria, del mismo modo que toda intuición de los sentidos pertenece, en cuanto idea, a una intuición interior pura, es decir, a la intuición del tiempo".32

El yo es, pues, la relación entre la "experiencia interior" (autoconciencia) y la "experiencia exterior" (conciencia del objeto): de esta manera queda salvada la cuestión metafísica insoluble hasta Kant de cómo se comunican el yo y las cosas absolutas (reales, del mundo exterior). Pues el yo y el objeto son ambos las manifestaciones de una misma estructura de leyes, es decir, las leyes de la "experiencia en general", que se manifiesta en el concepto de unidad monadológica de la apercepción trascendental. Mas esta última es el yo, y por consiguiente permanente e inmutable; pero relación inmutable sólo entre los contenidos y en modo alguno el sustrato del que surgen esos contenidos. Su doble condición de simple e indiviso se refiere al acto de síntesis de lo vario, y nada más. Por consiguiente, es totalmente ilegítimo pretender que de la unidad lógica de la función del pensamiento se infiere una sustancialidad real y metafísica del alma.

De donde se sigue —dice Kant_ que la primera deducción racional de la psicología trascendental sólo nos impone un criterio pretendidamente nuevo, ya que hace pasar el sujeto lógico constante del pensamiento por el conocimiento del sujeto real de la inherencia, del que no tenemos, ni podemos tener, la menor noción, ya que la conciencia es lo único que convierte todas nuestras representaciones en pensamientos y donde, por tanto, deben encontrarse todas nuestras percepciones como propias del sujeto trascendente y puesto que, aparte de esta significación logica del yo, no tenemos el menor conocimiento del sujeto de por sí que pueda servir, como sustrato, de base a éste y a todos los pensamientos. Sin embargo, no hay inconveniente en respetar la afirmación de que "el alma es la sustancia", siempre y cuando se tenga en cuenta que este concepto no puede hacernos dar un solo paso adelante, ni enseñarnos ninguna de las deducciones corrientes de la psicología especulativa, por ejemplo, la perpetuidad de la misma a través de todos los cambios e inclu-

31 E. Kant: Critica de la razón pura, "Lógica trascendental", libro II, cap. II, 15. 32 lbid. 
so después de la muerte del hombre; que, por tanto, sólo se trata de una sustancia en la idea, pero no en la realidad.33

Estas previas aclaraciones de la verdadera naturaleza del yo y el objeto, según Kant, permiten llegar a la dilucidación de ese otro concepto que recibe en su filosofía el nombre de "juicio sintético a priori". Como es sabido, Kant parte de una previa consideración de los tradicionales juicios analiticos y sintéticos: los primeros (tautológicos) son los que muestran un predicado que es parte esencial del sujeto ("todos los cuerpos son extensos"), mientras los segundos son aquellos cuyo predicado es accidental respecto del sujeto ("todos los cuerpos son pesados"); por lo cual dice Kant que los juicios analíticos pueden llamarse "explicativos" y los sintéticos "extensivos".

La experiencia es, pues, la que proporciona la sintesis del concepto al cual se aplica un predicado con el predicado nuevo, v. gr., la síntesis del concepto de "cuerpo" con el concepto de "pesado", pues - dice Kant"ambos conceptos, aunque en verdad no estén contenidos el uno en el otro, se pertenecen, sin embargo, de una manera contingente como partes de un todo, de la experiencia, que es un enlace sintético de intuiciones". ${ }^{34}$

Ahora bien, supongamos que se trata de la siguiente proposición: "todo lo que sucede tiene su causa". Vemos que el concepto de causa es algo distinto del "suceder" y, por lo mismo, no está comprendido en el primer concepto. A este respecto, dice Kant:

¿Cómo, pues, atribuir a lo que sucede algo que le es completamente extraño! ¿Y cómo conocer que el concepto de causa, aunque no comprendido en el de suceder, se le refiere, sin embargo, $y$ hasta le pertenece necesariamente? ¿Qué es esa incógnita $X$ en que se apoya el entendimiento cuando cree descubrir fuera del concepto $A$ un predicado que le es ajeno, y que, sin embargo, estima como unido a él? No puede ser la experiencia, puesto que la referida proposición reúne las dos representaciones, no sólo de un modo general, sino que también con el carácter de necesidad, es decir, a priori y por puros conceptos. En tales proposiciones sintéticas, es decir, extensivas, se funda todo el objeto final de nuestro conocimiento especulativo a priori; porque si bien las analíticas son muy importantes y muy necesarias, sólo sirven para lograr la claridad de los conceptos, que es tan indispensable para una segura y amplia síntesis como una nueva y real adquisición. 35

Para Kant los juicios sintéticos se encuentran en la matemática, en la física y en la metafísica. Así, en la suma $5+7=12$, el concepto de suma de cinco y siete sólo contiene la unión de dos números en uno solo, pero esto no determina que se piensa cuál es ese solo número que comprenda a los dos sumandos. Pues si en lugar de $5+7$ decimos $1276+348$, spodemos decir, al instante, cuál es el número que representa la suma correcta?

También la física, como ciencia de la naturaleza, contiene juicios sintéticos a priori, que son sus principios, v. gr. "en todos los cambios del mundo

33 E. Kant: Critica de la razón pura, "Lógica trascendental", libro II, 2.

34 E. Kant: Critica de la razón pura, Introducción, Iv.

35 Ibid. 
corpóreo la cantidad de materia permanece siempre la misma", o "en toda comunicación de movimiento la acción y la reacción deben siempre ser iguales".

Porque en el concepto de materia no percibo yo su persistencia, sino únicamente su presencia en el espacio que ocupa, y por tanto, voy más allá del concepto de materia para atribuirle algo a priori que no habia sido concebido en él. La proposición no ha sido, pues, concebida analítica, sino sintéticamente, aunque a priori, y asi sucede con las restantes proposiciones de la parte pura de la Física.36

Finalmente, la metafísica - aunque ciencia en ensayo- también se vale de juicios sintéticos a priori en tanto que ella pretende extender nuestros conocimientos a priori, "y para el efecto nos valemos de principios que a los conceptos dados añaden algo que no estaba comprendido en ellos", 37 v. gr. cuando decimos: "El mundo debe tener un primer principio, etc., etc.". Para Kant, "la metafísica consiste, al menos según su fin, en proposiciones puramente sintéticas a priori". 38

Vemos que Kant añade a la tradicional dualidad de los juicios analíticos y sintéticos una tercera forma, en que se combinan estos dos, o sea el "juicio sintético a priori". Ahora bien, debemos preguntar por la justificación de esta clase o género de juicio. Para Kant, no es la lógica general sino la lógica trascendental quien debe ocuparse con esta cuestión, ya que a ella toca "investigar la posibilidad de los juicios sintéticos a priori, sus condiciones y extensión de su valor". ${ }^{39}$ Pues de nada menos que del resultado de este cometido depende la posibilidad lógica de determinar los límites o el ámbito del entendimiento puro.

Recordemos que se ha hablado un poco antes de la "síntcsis a priori" y de la "unidad monadológica de la apercepción trascendental" y que hemos visto que mientras la primera es expresión de la trascendentalidad y ésta, a su vez, de la subjetividad (como lo entiende Kant), la segunda es esa estructura legal de la "experiencia en general", en la que se manifiestan sujeto y predicado. Entonces, si de acuerdo con Kant, es

... la experiencia, como síntesis empírica, en su posibilidad el único modo de conocimiento que da realidad a toda otra síntesis, ésta, como conocimiento a priori, no tiene verdad (no conforma con el objeto) sino en cuanto no contiene más que lo que es necesario a la unidad sintética de la experiencia en general,40

resulta, entonces, que no hay objeto que deje de estar regido por las condiciones que no pueden faltar nunca en esa unidad sintética de los diversos aspectos de una misma intuición en una experiencia posible.

36 Ibid.

87 Ibid, v.

38 Ibid.

39 E. Kant: Critica de la razón pura, "Lógica trascendental", libro II, cap. II, sec. $\mathbf{2}^{\mathbf{a}}$ 40 Ibid. 
Asi, son posibles los juicios sintéticos a priori cuando referimos las condiciones formales de la intuición a priori, la síntesis de la imaginación y su unidad necesaria en una apercepción trascendental, a un conocimiento experimental posible en general, y que decimos: las condiciones de la posibilidad de la experiencia en general son al mismo tiempo las de la posibilidad de los objetos de la experiencia, y por eso tienen un valor objetivo en un juicio sintético a priori.41

Entonces, es claro que si todo lo que constituye para mí una experiencia tiene que formar parte de la "posibilidad de la experiencia" en general, no puede haber nada en mi experiencia que no sea alcanzado por la condición predeterminante del juicio sintético a priori. Es más, sin esta condición no sería posible hablar de causalidad necesaria, por tanto, supraempírica, en el sentido de que no es la pura y simple "asociación de ideas" de Hume. Como el espacio, el tiempo, la sustancia, etc., también la causalidad es parte integrante de esas condiciones de la posibilidad de la experiencia en general. Por consiguiente, el juicio sintético a priori viene a ser la manifestación, en los objetos de la experiencia, de la causalidad que integra la posibilidad de la experiencia en general. Que se trata de un criterio firme de Kant, lo prueban las siguientes palabras suyas:

Cuando se considera a las mismas leyes de la Naturaleza como principios del uso empírico del Entendimiento, implican entonces un carácter de necesidad, y por consiguiente la presunción al menos de que están determinadas por principios que valen a priori, y anteriores a toda experiencia. Pero todas las leyes de la Naturaleza sin distinción están sujetas a principios superiores del Entendimiento, puesto que no son más que sus aplicaciones a casos particulares del fenómeno. Estos principios, por consecuencia, son los solos que dan la regla y en cierto modo el exponente de una regla en general, a la vez que la experiencia el caso que se ha de someter a la regla.42

\section{b) El espacio y el tiempo}

Quien quiera dar con los postulados fundamentales de la filosofía de Kant, tendrá que recurrir, sobre todo, a su doctrina particular del espacio y el tiempo. Pues es aquí donde topamos con esas expresiones kantianas en las cuales se contiene con clarísima brevedad la idea que nuestro filósofo tiene de la realidad en general, como al decir que "la propiedad del sujeto de ser afectado por las cosas precede necesariamente a todas las intuiciones de ellas".43 En esa necesaria, vale decir infaltable precedencia, se ofrece vigorosamente la radical traslación de lo objetivo a lo subjetivo. Y que se refuerza con esta otra consideración: "la materia de los fenómenos sólo puede dársenos a posteriori y [que] la forma de los mismos debe hallarse ya preparada

41 Ibid.

42 Ibid., sec. $3^{2}$.

43 E. Kant: Critica de la razón pura, "Estética trascendental", sec. 17, 2. 
a priori en el espíritu para todo en general, y que por consiguiente puede ser considerada independientemente de toda sensación". ${ }^{44}$

Kant, pues, funda las más importantes aseveraciones de su doctrina en el análisis del espacio y el tiempo, pues sin duda ha advertido que la descomunal empresa en que consiste la "inversión copernicana" no puede alcanzar todo el éxito de que debe estar asistida a menos que el pasaje a lo subjetivo se efectúe del más completo modo. $\mathrm{Y}$ esto último requiere que todo aquello que ha venido siendo considerado como propiedades o características de lo objetivo -espacio, tiempo, categorías - sea traspasado al sujeto, o mejor, que se demuestre que, sin discusión alguna, corresponde al sujeto. Ahora bien, ¿por qué desea o necesita probar Kant que esas mencionadas propiedades le corresponden al sujeto? "Los objetos - dice - nos son dados mediante la sensibilidad, y ella únicamente es la que nos ofrece las intuiciones; pero sólo el entendimiento los concibe y forma los conceptos." 45 Pero, ¿no es este algo muy parecido a lo que, respecto del proceso del conocimiento, establecen Berkeley y Hume? No temamos, empero, que suceda esto último, pues Kant se apresura a disolver la sospecha al decirnos: "Como las condiciones particulares de la sensibilidad no son las condiciones de la posibilidad de las cosas mismas, sino solamente la de sus fenómenos..." 46 Kant, pues, reitera una vez más su advertencia acerca de que el punto de partida no es el objeto sino el sujeto. Pero, que sea el punto de partida, no significa que el sujeto contenga ya en sí toda la realidad ni mucho menos; quiere decir, solamente, que él es -en cuanto sujeto - el centro de donde irradian las posibilidades del conocimiento de la realidad en general. Y la comprobación rigurosa de que es así como lo entiende Kant, la tenemos en los respectivos análisis del espacio y el tiempo.

Kant funda la subjetividad en estas cuatro claras y precisas consideraciones: I. El espacio no es un concepto empirico suministrable por la experiencia externa, porque si las sensaciones aluden a algo "fuera de mi" - a las cosas exteriores y simultáneas - es preciso que el sujeto que las percibe en los lugares en que se encuentran, tenga ya la representación del espacio. En consecuencia, la previa representación del espacio es la que posibilita la experiencia de los fenómenos del mundo exterior. II. Ni aun totalmente desprovisto de objetos es impensable el espacio: de aquí que sea "la condición de la posibilidad de los fenómenos y no como una determinación dependiente de ellos". III. No es un concepto discursivo -una definción- sino una intuición pura. Mas ¿qué entiende Kant por intuición pura? Él mismo se encarga de decirnos que es "aquella en la cual no se halla nada de lo que pertenece a la sensación. De aquí se deduce que la forma pura de la intui-

44 E. Kant: Critica de la razón pura, "Teoría elemental trascendental", ${ }^{\text {q }}$ parte, 1. 45 Ibid.

46 E. Kant: Critica de la razón pura, "Estética trascendental", sec. $1^{\text {a }}$, 3. 
ción sensible en general, en la que es percibida toda la diversidad de los fenómenos bajo ciertas relaciones, se encuentra a priori en el espíritu. Esta forma pura de la sensibilidad se llama también intuición pura". ${ }^{47} \mathrm{El}$ espacio es esencialmente uno, que intuido a priori sirve de base a todos los conceptos de espacio. IV. Finalmente, todas las partes del espacio coexisten en el infinito, pues de lo contrario "la primitiva representación del espacio" sería conceptual y no una intuición a priori.

De estas cuatro premisas sobre la verdadera naturaleza del espacio, se desprenden las siguientes conclusiones: que "el espacio no representa ninguna propiedad de las cosas, ya se las considere en sí mismas o en sus relaciones entre si"; que "no es más que la forma de los fenómenos de los sentidos externos, es decir, la única condición subjetiva de la sensibilidad, mediante la que nos es posible la intuición externa"; que "nada significa la representación del espacio si salimos de la condición subjetiva, bajo la que únicamente podemos recibir la intuición externa, es decir, ser afectados por los objetos". $Y$ concluye Kant diciéndonos:

Afirmamos, pues, la realidad empirica del Espacio en relación a toda experiencia externa posible; pero reconocemos también la idealidad trascendental del mismo, es decir, su no existencia, desde el momento en que abandonamos las condiciones de posibilidad de toda experiencia y le creemos algo que sirve de fundamento a las cosas en si.48

Por consiguiente, la cosa en sí - la famosa Ding an sich- no tiene razón de ser desde el momento en que el espacio no es, en modo alguno, el fundamento del mundo exterior.

Al contrario, el concepto trascendental de los fenómenos en el Espacio nos sugiere la observación critica de que nada de lo que es percibido en el Espacio es una cosa en sí, y que tampoco es el Espacio una forma de las cosas consideradas en sí mismas, sino que las cosas que nos son desconocidas en sí mismas que llamamos objetos externos son simples representaciones de nuestra sensibilidad, cuya forma es el Espacio, pero cuyo verdadero correlativo, esto es, la cosa en sí, nos es totalmente desconocida, y lo será siempre por ese medio; mas por ella no se pregunta nunca en la experiencia.49

Si pasamos ahora a la subjetividad del tiempo, veremos a Kant apoyarla en estas cinco consideraciones: I. No puede darse la simultaneidad o la sucesión a menos que exista una representación a priori del tiempo que les sirve de soporte. II. El tiempo no se puede eliminar de los fenómenos en general, pero éstos se pueden separar de él, lo cual es posible sólo porque el tiempo está dado a priori. III. Esta aprioridad es la que fundamenta los axiomas de la unidimensionalidad, la sucesividad (no simultaneidad) de los diferentes tiempos. IV. Como el espacio, el tiempo no es un concepto, sino una intuición pura o "una forma pura de la intuición sensible. V..El

47 E. Kant: Critica de la razón pura, “Teoria elemental trascendental", I, 1.

48 E. Kant: Critica de la razón pura, "Estética trascendental", sec. 1", 3. 49 Ibid. 
tiempo es infinito, pues "toda cantidad determinada de tiempo es solamente posible por las limitaciones de un único tiempo que les sirve de fundamento".50

También estas premisas implican ciertas consecuencias, como son: que no hay autosubsistencia del tiempo, ni él es una determinación objetiva de las cosas; que él es "la forma del sentido interno" o sea de "la intuición de nosotros mismos y de nuestros estados interiores", y además "determina la relación de las representaciones en nuestros estados internos"; que él es "la condición formal a priori de todos los fenómenos en general".

Creo que después de todo lo expuesto, ninguna duda puede quedar acerca de la eminente subjetividad de la noción de realidad en Kant. Las respectivas concepciones del espacio y el tiempo, como "formas" de la sensibilidad, son aquellas mediante las cuales se hace posible la experiencia en general, y ésta a su vez se da en el hombre a través de los fenómenos: dichas respectivas concepciones constituyen el más valioso fundamento de la inversión copernicana.

\section{c) Las categorias}

La subjetividad fundada en la trascendentalidad y la șintesis a priori, por una parte; el espacio y el tiempo por la otra, hacen inevitable el desplazamiento de las categorias - de esas "flexiones" o "analogias del ente", como las llamó Aristóteles- desde el objeto al sujeto. Pues una vez que el espacio y el tiempo ya no pertenecen al objeto, al mundo de la experiencia externa, sino que son determinaciones que en ésta imprime la subjetividad trascendental, no hay manera de seguir concibiendo que las propiedades fundamentales del ente, o sea las categorías, le pertenezcan originariamente y con carácter inalienable. Por consiguiente, de la expresión de Kant: "Decimos que conocemos al objeto cuando hemos logrado dar una unidad sintética a la variedad de la intuición", sólo puede desprenderse la conclusión de que esa unidad sintética debe producirse a causa de ciertas "formas" que, reducidas a términos lógicos, constituyen los juicios. Éstos son, pues, para Kant, la posibilidad de todo análisis, porque antes lo han sido de toda síntesis, "pues alli donde el entendimiento no ha asociado previamente no puede tampoco disociar, pues sólo por medio de él puede asociar la imaginación". ${ }^{51}$ De este modo, resulta que es una misma función la que dota de unidad a las diferentes ideas de un juicio y a la diversidad de los elementos sensoriales para que éstos tengan una validez objetiva:

Es, por tanto, el mismo intelecto, y además por medio de los mismos actos con los que crea en conceptos, por medio de la unidad analítica, la forma lógica de un juicio, el

50 Ibid., sec. $2^{\mathrm{a}}, 4$.

51 E. Kant: Critica de la razón pura, “Análisis trascendental", libro I, cap. 1, sec. $3^{\text {a }}$ 
que mediante la unidad sintética de lo múltiple crea en la intuición, a través de sus ideas, un contenido trascendental, razón por la cual esos conceptos reciben el nombre de conceptos intelectivos puros, que versan a priori sobre objetos, misión que la lógica formal no puede desempeñar.52

Ahora bien, desde el momento que las categorias constituyen ciertas "formas" con las que el juicio opera en la realidad sensorial y determina la unidad sintética de sus diversos elementos, las categorías no pueden ser consideradas, según lo hace Aristóteles, como simples caracteres o atributos del ente. Por el contrario, la categoría no es una forma del ente, sino más bien éste es una forma de lo categorial. Y conforme con este criterio suyo expresa Kant lo siguiente:

Aristóteles había reunido bajo el nombre de categorías diez conceptos elementales puros. A éstos, llamados también predicamentos, vióse obligado a añadirles más tarde otros cinco postpredicamentos, que en parte iban ya implícitos en aquéllos (como prius, simul, motus) ; sin embargo, esta rapsodia podía ser considerada más bien como una orientación para el investigador futuro que como una idea normalmente desarrollada... Investigando los elementos puros (es decir, que no encierran nada empírico) del conocimiento humano, he conseguido por vez primera, tras larga reflexión, distinguir y diferenciar claramente los conceptos elementales puros de los sentidos (el espacio y el tiempo) de los del entendimiento. Con ello quedaban eliminadas de aquel indice las categorias séptima, octava y novena. Las demás no podían servirme de nada, ya que no existía ningún principio con arreglo al cual pudiera medirse íntegramente el entendimiento y determinarse completamente y con precisión absoluta todas las funciones de él de donde surgen sus conceptos puros. Ahora bien, para descubrir este principio volvía la vista hacia una operación del entendimiento que encierra todo lo demás y que sólo se distingue por medio de diversos momentos o modificaciones encaminados a reducir lo múltiple de las ideas a la unidad del pensamiento, y entonces me di cuenta de que esta operación del entendimiento consistía en juzgar. Tenía ante mí el trabajo ya terminado de los lógicos, aunque no libre de defectos, por medio del cual pude llegar a formar una tabla completa de funciones intelectivas puras, aunque indeterminadas en cuanto al objeto. Finalmente, referí estas funciones del juicio a objetos en general o más bien a la condición de determinar los juicios como objetivamente valederos, y surgieron asi los juicios intelectivos puros, con respecto a los cuales podía estar seguro que eran precisamente ellos, y solamente ellos, ni más ni menos, los que podían determinar todo nuestro conocimiento de las cosas a base del simple entendimiento.53

Las consecuencias de este razonamiento son las siguientes: I) distinción entre intuiciones puras de espacio y tiempo (conceptos elementales puros de los sentidos) y las categorías propiamente dichas; con lo cual, de paso, hace Kant una depuración y desecha las tres últimas categorías aristotélicas (posición, acción y pasión). 2) Sin embargo, las restantes categorías aristotélicas no le sirven a Kant, porque éstas se refieren al ente y no al entendimiento. ¿Cómo descubrir en dónde reside la verdadera naturaleza de este último, que ha de ser una función, puesto que no es nada más? Pues bien, en la opera-

52 Ibid.

53 E. Kant: Prolegómenos, 39. 
ción del juzgar, que reduce la multiplicidad de las ideas a la unidad del pensamiento, consiste el entendimiento. En consecuencia, el juicio es la posibilidad de los objetos en general, por cuanto de su función sintética de las ideas se deriva la unidad objetiva de los elementos sensoriales; y si, en cuanto juicio, realiza tal sintesis eidética, no puede dudarse que, en esta operación, pone al mismo tiempo de manifiesto las únicas formas posibles de las categorías.

La trayectoria del razonamiento que aqui describe Kant corresponde totalmente a su tendencia general fundamental. Aristóteles habia determinado los "elementos" del conocimiento, y Kant se propone descubrir el "principio" en que estos. elementos se basan; y así como Aristóteles arrancaba de las cualidades originarias del ser, Kant se remonta al juicio como a la unidad del acto lógico, que da constancia y necesidad y, por tanto, validez objetiva al contenido de nuestras ideas. 54

Después de estas previas y necesarias aclaraciones, se hace bástante claro por qué Kant hace derivar de su sistema de los juicios el sistema de las categorías.

Si abstraemos todo el contenido de un juicio en general y solamente atendemos a la pura forma del entendimiento, encontraremos que la función del pensar en el juicio puede comprenderse bajo cuatro títulos que contienen respectivamente cada uno tres momentos. Pueden ser fácilmente representados en la siguiente tabla: 55

Cuantidad de los juicios

$\begin{array}{llc} & \begin{array}{l}\text { Generales } \\ \text { Particulares } \\ \text { Singulares }\end{array} \\ \begin{array}{l}\text { Cualidad } \\ \text { Afirmativos }\end{array} & \\ \text { Negativos } & & \begin{array}{c}\text { Relación } \\ \text { Indefinidos }\end{array} \\ & & \begin{array}{c}\text { Categóricos } \\ \text { Hipotéticos } \\ \text { Disyuntivos }\end{array} \\ & \text { Modalidad } & \\ & \text { Problemáticos } & \\ & \text { Asertóricos } & \\ \text { Apodícticos } & \end{array}$

Como se acaba de expresar, para Kant las categorías deben sobrevenir al sistema de los juicios, por estas fundamentales razones:

La misma función que da unidad a las diferentes representaciones en un solo juicio es la que da también unidad a la simple sintesis de diferentes representaciones en una sola intuición, la cual, en sentido general, se llama concepto puro del entendimiento. Ejerciendo precisamente el entendimiento las mismas operaciones, en virtud de las cuales da a los conceptos la forma lógica de un juicio, mediante la unidad analítica, introduce también una materia trascendental en sus representaciones mediante la unidad sintética de los elementos diversos en la intuición en general. Por esta razón se llaman conceptos puros

54 E, Cassirer: $O p$. cit., II, 3 .

55 E. Kant: Critica de la razón pura, "Análisis trascendental", libro I, cap. I, sec. 29. 
intelectuales que se refieren a priori a los objetos, lo cual no resulta de la Lógica en general.56

De cuantidad
Unidad
Pluralidad
Totalidad

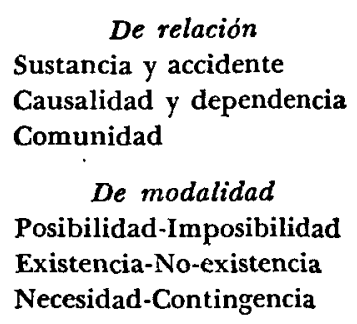

\author{
De relación \\ Sustancia y accidente \\ Causalidad y dependencia \\ Comunidad \\ De modalidad \\ Posibilidad-Imposibilidad \\ Existencia-No-existencia \\ Necesidad-Contingencia
}

Ahora bien, notemos que Kant introduce una modificación sumamente llamativa, cual es la de presentar como una sola categoría a la sustancia y el accidente; con esto no sólo se aparta del punto de vista aristotélico -quien, como sabemos, hace de la sustancia la primera categoría-, sino que tanto ésta como el accidente quedan convertidos en los dos aspectos de otra categoría, a saber, la de relación. Pero hay más, y es que esta última categoría -que opera según tres denominaciones diferentes-, es esencialmente categoria de lo temporal, o sea que el tiempo funciona a través de ella. Además, las categorias de sustancia y causalidad -como todas las que integran el sistema kantiano- se refieren a los fenómenos y jamás al ser mismo, o al menos al ente.

De la forma en que Kant agrupa bajo una misma categoría fundamental -la de relación - la sustancialidad y la causalidad (no nos interesa ahora la comunidad), se desprende que la duración (sustancia) y el cambio (causa) están recíprocamente implicados. A este respecto, dice Cassirer lo siguiente:

Por ejemplo, para determinar en un sentido objetivo la aparición de un cambio no basta con que admitamos la existencia de diversos contenidos y los colguemos, por decirlo así, en diversos momentos en el tiempo - ya que ni el tiempo ni el momento de por sí son objetos de posible percepción-, sino que para ello debemos encontrar en los fenómenos mismos un algo permanente e invariable con relación al cual podamos poner de relieve el cambio operado en otros determinados aspectos. Esta idea de una constante relativa y de un algo relativamente mudable en los fenómenos, esta categoría de sustancia y accidente constituye, por tanto, la condición necesaria bajo la cual se destaca para nosotros de entre la totalidad de nuestras ideas el concepto de la unidad del tiempo, de la duración dentro del cambio. 57

Examinemos ahora brevemente la refutación kantiana del rechazo que hace Hume de la causalidad. Es claro, advierte Kant, que el escocés tiene

56 Ibid., sec. $3^{3}$

57 E. Cassirer: $O p$. cit., III, 3. 
razón al concluir que, a lo sumo, podemos establecer que los fenómenos se suceden unos a otros, que acabamos reemplazándolos en nuestra imaginación por "asociaciones de ideas" relativamente fijas. Kant procede a demostrar que el concepto de causalidad no puede derivar de la regularidad en la sucesión de las sensaciones y las ideas, sino que, por el contrario, "son... este concepto, la idea y el postulado de una regla aplicadas por nosotros a las percepciones, las que nos permiten dar una 'forma' determinada a la serie siempre igual en que fluyen, destacar en ellas ciertos entronques objetivamente necesarios, $y$, de este modo, dar 'objetividad' a nuestras ideas". 58

Pero, como dice el propio Kant, si deseamos saber mediante qué cualidades se relacionan nuestras ideas con los objetos, vemos que

... lo único que hace es infundir un carácter de necesidad a ciertas asociaciones de ideas y someterlas al imperio de una regla y que, por el contrario, el único modo de atribuir una significación objetiva a nuestras ideas consiste en pensar que entre sus relaciones en el tiempo media un cierto orden necesario.58

Y de aquí que al colocar cualquier relación empírica bajo el concepto de causalidad, lo que hacemos es establecer univocamente el orden de sucesión de sus elementos en el tiempo.

Supongamos que un acaecimiento no vaya precedido por nada de lo que este acaecimiento tenga necesariamente que derivarse conforme a una regla: en estas condiciones, toda la sucesión de las percepciones residiría solamente en la aprehensión, es decir, sería simplemente subjetiva, pero de ese modo no se determinaría objetivamente en modo alguno qué debiera ser lo anterior y qué lo posterior en el orden de las percepciones. Por este camino sólo tendríamos un juego de ideas que no se referiria a objeto alguno, es decir, no podríamos distinguir por medio de la percepción unos fenómenos de otros dentro de su sucesión en el tiempo... No diríamos, pues, que dos estados se sucedían el uno al otro en su manifestación, sino simplemente que una aprehensíon seguía a otra, lo cual es algo puramente subjetivo, que no determina ningún objeto y que, por tanto, no puede ser considerado... como conocimiento de un objeto cualquiera... Trátase, por consiguiente..., de poner de relieve que no somos nunca nosotros mismos los que en la experiencia imponemos el orden de sucesión al objeto... y lo distinguimos del orden subjetivo de nuestras aprehensiones, como si rigiese una regla que nos obligara a sujetarnos a este orden de percepciones con preferencia a otro cualquiera, más aún, que es esta coacción la que en rigor hace posible la idea de una sucesión en cuanto al objelo.60

La causalidad no es, pues, para Kant algo así como un poder objetivo - -especie de fatalidad asentada en las propias cosas-, que en Hume se convierte en fatalidad "subjetiva" (la asociación de ideas). Kant, por su parte, entiende que la relación causal se funda en esa sintesis necesaria de nuestro entendimiento que plasma en experiencias las impresiones regulares y aisladas.

58 Ibid.

59 E. Kant: Critica de la razón pura, "Logica trascendental", cap. II.

60 E. Kant: Crítica de la razón pura, "Análisis trascendental", libro I, cap. II. 
d) La "cosa en si"

Estamos ahora a un paso de la respuesta que proporciona el examen kantiano de la causalidad, es a saber, la que se contiene en la misma crítica de la razón pura, cuya misión ha sido "la de averiguar las condiciones generales y necesarias de todos los juicios objetivos y, por tanto, de todas las concepciones también objetivas que son posibles dentro de la experiencia". ${ }^{61}$ La respuesta, entonces, consiste previamente en decirnos que el objeto empírico -o sea las cosas del mundo exterior - es pura y simplemente el "objeto del fenómeno", que es, trascendentalmente considerado, el objeto de una posible experiencia. Y es aqui precisamente en donde surge, nítida y categórica, la respuesta kantiana al escepticismo de Hume: que el conocimiento jamás lo es del objeto "en sí y por sí", sino del fenómeno, es decir, mediante las formas de la intuición pura (espacio y tiempo) y del pensamiento puro (las categorías). Pero, cabe preguntar: tno se puede, entonces, hablar del objeto sin que esté sometido a esas "condiciones", o sea que no cabe hablar del objeto "real"?

A este respecto, dice Cassirer:

Si se nos ocurriera preguntar qué podría ser el objeto si prescindiéramos de todos estos momentos constitutivos de su concepto, si dejásemos de concebirlo dentro del espacio y el tiempo, como una magnitud extensiva o intensiva, si lo enfocásemos sin relación alguna con las condiciones de sustancialidad, de causalidad, de interdependencia, etc., planteariamos con ello un problema que como tal no encierra, hay que reconocerlo, ninguna contradicción interna. En efecto, esta contradicción sólo surge allí donde unimos en un concepto y los concebimos, por tanto, conjuntamente dos predicados positivos contrapuestos entre sí; pero aquí no concebimos, en realidad, nada, sino que nos limitamos a establecer las condiciones de toda concepción en general, ya conocidas de nosotros. Resultado de esto no es una contradicción, ciertamente, pero sí es la pura nada, siempre y cuando no pueda señalarse ya ni cl menor fundamento para la idea de semejante objeto existente de por sí, fuera de toda relación con las leyes formales del conocimiento. La idea es posible, indudablemente, en función analítica, conforme a las reglas de la lógica formal, pero no es valedera en función sintética, como contenido real del conocimiento.62

$\mathrm{Y}$ es que, en definitiva, Kant se afianza en la distinción entre la idea y el concepto, aunque la distinción sea más implícita que explicita. Pues aunque él se refiere a los conceptos puros del entendimiento, como las formas desprovistas de contenido que hacen posible la experiencia en general, debemos tener presente que él se propone reservar la idea para lo que no es producto de la experiencia.

En una palabra, todos estos conceptos no pueden documentarse en modo alguno ni es posible, por tanto, exponer su posibilidad real si se deja a un lado toda intuición sensorial (la única que poseemos), y en este caso sólo quedará en pie la posibilidad lógica, es

61 E. Cassirer: $O p$. cit., mI, 4 .

Q2 Ibid. 
decir, la de que sea posible el concepto (la idea), pero no es de esto de lo que se trata, sino de saber si realmente se refiere a un objeto y si, por tanto, significa algo.63

La idea, pues, diríamos que difiere del concepto, en sentido kantiano, en que mientras éste pertenece al entendimiento, aquélla corresponde a la razón pura: pues "los principios del entendimiento puro sólo pueden ser referidos a las condiciones generales de una experiencia posible, a los objetos de los sentidos, nunca a las cosas en general (sin fijarnos para nada en el modo como podamos verlos a través de los sentidos)". ${ }^{64}$

No se refiere la razón directamente a un objeto, sino al entendimiento, y por medio de éste a su propio uso empírico. No crea la razón conceptos objetivos, sino que tiende a ordenarlos y a suministrarles la unidad que pueden tener en su mayor extensión posible, vale decir, por relación a la totalidad de las series, totalidad que no percibe el entendimiento, entretenido sólo en el encadenamiento por el cual las series de condiciones son siempre constituidas según conceptos. No tiene, pues, la razón, por objeto, más que el entendimiento y su empleo conforme a un fin, e igual que éste une por conceptos lo múltiple en el objeto, aquélla reúne por ideas lo múltiple de los conceptos, buscando cierta unidad colectiva o común como fin a los actos del entendimiento, el cual, sin esto, sólo podría ocuparse de la unidad distributiva. Afirmo, por tanto, que las ideas trascendentales no tienen nunca un uso constitutivo que suministre conceptos de ciertos objetos, y que, en el caso de que se entienda asi, son simples conceptos sofísticos (dialéc. ticos). En cambio, tienen un uso regulador indispensable, que es el de dirigir el entendimiento hacia determinado fin que hace converger las líneas directivas que siguen sus reglas a un punto que, por no ser más que una idea (focus imaginarius), vale decir, un punto de donde los conceptos del entendimiento no parten en realidad, ya que se halla fuera de los límites de la experiencia posible, sirve, no obstante, para procurarles la mayor unidad con la más absoluta extensión. Para nosotros resulta, sin embargo, una ilusión de tal naturaleza, que todas esas líneas nos parecen proceder de un objeto situado fuera del campo del conocimiento empírico posible (como si los objetos se percibieran detrás de la superficie del espacio); mas esta ilusión, que puede ser equivocada, no es necesaria inevitablemente si, además de los objetos que se encuentran ante nuestra vista, queremos ver a la vez los que se hallan lejos de ellos, esto es, si queremos colocar el entendimiento más allá de toda experiencia dada (formando parte de toda experiencia posible), tratando de alcanzar la mayor extensión, aun la más absurda.65

El noumenos (la "cosa en sí") es, pues, para la doctrina kantiana del conocimiento, un concepto puramente problemático, y lejos de ser un objeto inteligible, que nuestro entendimiento puede asimilar, sucedería todo lo contrario, o sea "que el entendimiento que se lo asimilase es, a su vez, un problema".

La cuestión, sin embargo, queda en pie: ¿cómo conciliar la "realidad" del nóumeno con la "realidad" ya probada del conocimiento trascendental? Kant ensaya la respuesta afirmativa en las dos Criticas subsiguientes (prácti-

63 E. Kant: Critica de la razón pura, "Lógica trascendental", cap. III.

64 E. Kant: Critica de la razón pura, ibid.

65 E. Kant: Critica de la razón pura, "Apéndice a la lógica trascendental". 
ca _la ética-y del juicio - la estética). Y al hacerlo, intenta demostrar que es efectivamente posible separar lo sensible de lo inteligible, el fenómeno de la cosa en sí. Pero ésta es ya otra tarea, que rebasa decisivamente el fin a que se contraen estas notas.

Humberto Piñera Llera 